\title{
Strong convergence of a hybrid method for monotone variational inequalities and fixed point problems
}

\author{
Yonghong Yao ${ }^{1}$, Yeong-Cheng Liou', Mu-Ming Wong ${ }^{3^{*}}$ and Jen-Chih Yao ${ }^{4}$
}

\author{
* Correspondence: \\ mmwong@cycu.edu.tw \\ ${ }^{3}$ Department of Applied \\ Mathematics, Chung Yuan Christian \\ University, Chung Li 32023, Taiwan \\ Full list of author information is \\ available at the end of the article
}

\begin{abstract}
In this paper, we suggest a hybrid method for finding a common element of the set of solution of a monotone, Lipschitz-continuous variational inequality problem and the set of common fixed points of an infinite family of nonexpansive mappings. The proposed iterative method combines two well-known methods: extragradient method and CQ method. Under some mild conditions, we prove the strong convergence of the sequences generated by the proposed method.

Mathematics Subject Classification (2000): 47H05; 47H09; 47H10; 47J05; 47J25.
\end{abstract}

Keywords: variational inequality problem, fixed point problems; monotone mapping, nonexpansive mapping, extragradient method, CQ method, projection

\section{Introduction}

Let $H$ be a real Hilbert space with inner product $\langle\cdot, \cdot\rangle$ and induced norm $\|\cdot\|$. Let $C$ be a nonempty closed convex subset of $H$. Let $A: C \rightarrow H$ be a nonlinear operator. It is well known that the variational inequality problem $\operatorname{VI}(C, A)$ is to find $u \in C$ such that

$$
\langle A u, v-u\rangle \geq 0, \quad \forall v \in C .
$$

The set of solutions of the variational inequality is denoted by $\Omega$.

Variational inequality theory has emerged as an important tool in studying a wide class of obstacle, unilateral and equilibrium problems, which arise in several branches of pure and applied sciences in a unified and general framework. Several numerical methods have been developed for solving variational inequalities and related optimization problems, see $[1,1-25]$ and the references therein. Let us start with Korpelevich's extragradient method which was introduced by Korpelevich [6] in 1976 and which generates a sequence $\left\{x_{n}\right\}$ via the recursion:

$$
\left\{\begin{array}{l}
y_{n}=P_{C}\left[x_{n}-\lambda A x_{n}\right], \\
x_{n+1}=P_{C}\left[x_{n}-\lambda A y_{n}\right], n \geq 0,
\end{array}\right.
$$

where $P_{C}$ is the metric projection from $R^{n}$ onto $C, A: C \rightarrow H$ is a monotone operator and $\lambda$ is a constant. Korpelevich [6] proved that the sequence $\left\{x_{n}\right\}$ converges strongly to a solution of $V I(C, A)$. Note that the setting of the space is Euclid space $R^{n}$.

(c) 2011 Yao et al; licensee Springer. This is an Open Access article distributed under the terms of the Creative Commons Attribution License (http://creativecommons.org/licenses/by/2.0), which permits unrestricted use, distribution, and reproduction in any medium, provided the original work is properly cited. 
Korpelevich's extragradient method has extensively been studied in the literature for solving a more general problem that consists of finding a common point that lies in the solution set of a variational inequality and the set of fixed points of a nonexpansive mapping. This type of problem aries in various theoretical and modeling contexts, see e.g., [16-22,26] and references therein. Especially, Nadezhkina and Takahashi [23] introduced the following iterative method which combines Korpelevich's extragradient method and a $C Q$ method:

$$
\begin{aligned}
& x_{0}=x \in C, \\
& y_{n}=P_{C}\left[x_{n}-\lambda_{n} A x_{n}\right], \\
& z_{n}=\alpha_{n} x_{n}+\left(1-\alpha_{n}\right) S P_{C}\left[x_{n}-\lambda_{n} A y_{n}\right], \\
& C_{n}=\left\{z \in C:\left\|z_{n}-z\right\| \leq\left\|x_{n}-z\right\|\right\}, \\
& Q_{n}=\left\{z \in C:\left\langle x_{n}-z, x-x_{n}\right\rangle \geq 0\right\}, \\
& x_{n+1}=P_{C_{n} \cap Q_{n}} x, n \geq 0, n \geq 0,
\end{aligned}
$$

where $P_{C}$ is the metric projection from $H$ onto $C, A: C \rightarrow H$ is a monotone $k$-Lipschitz-continuous mapping, $S: C \rightarrow C$ is a nonexpansive mapping, $\left\{\lambda_{n}\right\}$ and $\left\{\alpha_{n}\right\}$ are two real number sequences. They proved the strong convergence of the sequences $\left\{x_{n}\right\},\left\{y_{n}\right\}$ and $\left\{z_{n}\right\}$ to the same element in $\operatorname{Fix}(S) \cap \Omega$. Ceng et al. [25] suggested a new iterative method as follows:

$$
\begin{aligned}
& y_{n}=P_{C}\left[x_{n}-\lambda_{n} A x_{n}\right], \\
& z_{n}=\alpha_{n} x_{n}+\left(1-\alpha_{n}\right) S_{n} P_{C}\left[x_{n}-\lambda_{n} A y_{n}\right], \\
& C_{n}=\left\{z \in C:\left\|z_{n}-z\right\| \leq\left\|x_{n}-z\right\|\right\}, \\
& \text { find } x_{n+1} \in C_{n} \text { such that } \\
& \left\langle x_{n}-x_{n+1}+e_{n}-\sigma_{n} A x_{n+1}, x_{n+1}-x\right\rangle \geq-\varepsilon_{n}, \quad \forall x \in C_{n},
\end{aligned}
$$

where $A: C \rightarrow H$ is a pseudomonotone, $k$-lipschitz-continuous and $(w, s)$-sequentially-continuous mapping, $\left\{S_{i}\right\}_{i=1}^{N}: C \rightarrow C$ are $N$ nonexpansive mappings. Under some mild conditions, they proved that the sequences $\left\{x_{n}\right\},\left\{y_{n}\right\}$ and $\left\{z_{n}\right\}$ converge weakly to the same element of $\bigcap_{i=1}^{N} \operatorname{Fix}\left(S_{i}\right) \cap \Omega$ if and only if $\lim _{\inf _{n}}\left\langle A x_{n}, x-x_{n}\right\rangle \geq 0, \forall x \in C$. Note that Ceng, Teboulle and Yao's method has only weak convergence. Very recently, Ceng, Hadjisavvas and Wong further introduced the following hybrid extragradientlike approximation method

$$
\begin{aligned}
& x_{0} \in C, \\
& y_{n}=\left(1-\gamma_{n}\right) x_{n}+\gamma_{n} P_{C}\left[x_{n}-\lambda_{n} A x_{n}\right], \\
& z_{n}=\left(1-\alpha_{n}-\beta_{n}\right) x_{n}+\alpha_{n} y_{n}+\beta_{n} S P_{C}\left[x_{n}-\lambda_{n} A y_{n}\right], \\
& C_{n}=\left\{z \in C:\left\|z_{n}-z\right\|^{2} \leq\left\|x_{n}-z\right\|^{2}+\left(3-3 \gamma_{n}+\alpha_{n}\right) b^{2}\left\|A x_{n}\right\|^{2}\right\}, \\
& Q_{n}=\left\{z \in C:\left\langle x_{n}-z, x_{0}-x_{n}\right\rangle \geq 0\right\}, \\
& x_{n+1}=P_{C_{n} \cap Q_{n}} x_{0},
\end{aligned}
$$

for all $n \geq 0$. It is shown that the sequences $\left\{x_{n}\right\},\left\{y_{n}\right\},\left\{z_{n}\right\}$ generated by the above hybrid extragradient-like approximation method are well defined and converge strongly to $P_{F(S) \cap \Omega}$.

Motivated and inspired by the works of Nadezhkina and Takahashi [23], Ceng et al. [25], and Ceng et al. [27], in this paper we suggest a hybrid method for finding a common element of the set of solution of a monotone, Lipschitz-continuous variational inequality problem and the set of common fixed points of an infinite family of 
nonexpansive mappings. The proposed iterative method combines two well-known methods: extragradient method and $C Q$ method. Under some mild conditions, we prove the strong convergence of the sequences generated by the proposed method.

\section{Preliminaries}

In this section, we will recall some basic notations and collect some conclusions that will be used in the next section.

Let $C$ be a nonempty closed convex subset of a real Hilbert space $H$. A mapping $A$ : $C \rightarrow H$ is called monotone if

$$
\langle A u-A v, u-v\rangle \geq 0, \forall u, v \in C .
$$

Recall that a mapping $S: C \rightarrow C$ is said to be nonexpansive if

$$
\|S x-S y\| \leq\|x-y\|, \forall x, y \in C .
$$

Denote by $\operatorname{Fix}(S)$ the set of fixed points of $S$; that is, $\operatorname{Fix}(S)=\{x \in C: S x=x\}$.

It is well known that, for any $u \in H$, there exists a unique $u_{0} \in C$ such that

$$
\left\|u-u_{0}\right\|=\inf \{\|u-x\|: x \in C\} .
$$

We denote $u_{0}$ by $P_{C}[u]$, where $P_{C}$ is called the metric projection of $H$ onto $C$. The metric projection $P_{C}$ of $H$ onto $C$ has the following basic properties:

(i) $\left\|P_{C}[x]-P_{C}[y]\right\| \leq\|x-y\|$ for all $x, y \in H$.

(ii) $\left\langle x-P_{C}[x], y-P_{C}[x]\right\rangle \leq 0$ for all $x \in H, y \in C$.

(iii) The property (ii) is equivalent to

$$
\left\|x-P_{C}[x]\right\|^{2}+\left\|y-P_{C}[x]\right\|^{2} \leq\|x-y\|, \forall x \in H, y \in C .
$$

(iv) In the context of the variational inequality problem, the characterization of the projection implies that

$$
u \in \Omega \Leftrightarrow u=P_{C}[u-\lambda A u], \forall \lambda>0 .
$$

Recall that $H$ satisfies the Opial's condition [28]; i.e., for any sequence $\left\{x_{n}\right\}$ with $x_{n}$ converges weakly to $x$, the inequality

$$
\lim _{n \rightarrow \infty} \inf \left\|x_{n}-x\right\|<\lim _{n \rightarrow \infty} \inf \left\|x_{n}-y\right\|
$$

holds for every $y \in H$ with $y \neq x$.

Let $C$ be a nonempty closed convex subset of a real Hilbert space $H$. Let $\left\{S_{i}\right\}_{i=1}^{\infty}$ be infinite family of nonexpansive mappings of $C$ into itself and let $\left\{\xi_{i}\right\}_{i=1}^{\infty}$ be real number sequences such that $0 \leq \xi_{i} \leq 1$ for every $i \in \mathbf{N}$. For any $n \in \mathbf{N}$, define a mapping $W_{n}$ of $C$ into itself as follows:

$$
\begin{aligned}
& U_{n, n+1}=I, \\
& U_{n, n}=\xi_{n} S_{n} U_{n, n+1}+\left(1-\xi_{n}\right) I, \\
& U_{n, n-1}=\xi_{n-1} S_{n-1} U_{n, n}+\left(1-\xi_{n-1}\right) I, \\
& \quad \vdots \\
& U_{n, k}=\xi_{k} S_{k} U_{n, k+1}+\left(1-\xi_{k}\right) I, \\
& U_{n, k-1}=\xi_{k-1} S_{k-1} U_{n, k}+\left(1-\xi_{k-1}\right) I, \\
& \quad \vdots \\
& U_{n, 2}=\xi_{2} S_{2} U_{n, 3}+\left(1-\xi_{2}\right) I, \\
& W_{n}=U_{n, 1}=\xi_{1} S_{1} U_{n, 2}+\left(1-\xi_{1}\right) I .
\end{aligned}
$$


Such $W_{n}$ is called the $W$-mapping generated by $\left\{S_{i}\right\}_{i=1}^{\infty}$ and $\left\{\xi_{i}\right\}_{i=1}^{\infty}$.

We have the following crucial Lemmas 3.1 and 3.2 concerning $W_{n}$ which can be found in [29]. Now we only need the following similar version in Hilbert spaces.

Lemma 2.1. Let $C$ be a nonempty closed convex subset of a real Hilbert space $H$. Let $S_{1}, S_{2}, \ldots$ be nonexpansive mappings of $C$ into itself such that $\bigcap_{n=1}^{\infty}$ Fix $\left(S_{n}\right)$ is nonempty, and let $\xi_{1}, \xi_{2}, \ldots$ be real numbers such that $0<\xi_{i} \leq b<1$ for any $i \in \mathbf{N}$. Then, for every $x \in C$ and $k \in \mathbf{N}$, the limit $\lim _{n \rightarrow \infty} U_{n, k} x$ exists.

Lemma 2.2. Let $C$ be a nonempty closed convex subset of a real Hilbert space H. Let $S_{1}, S_{2}, \ldots$ be nonexpansive mappings of $C$ into itself such that $\bigcap_{n=1}^{\infty}$ Fix $\left(S_{n}\right)$ is nonempty, and let $\xi_{1}, \xi_{2}, \ldots$ be real numbers such that $0<\xi_{i} \leq b<1$ for any $i \in N$. Then, $\operatorname{Fix}(W)=\bigcap_{n=1}^{\infty} \operatorname{Fix}\left(S_{n}\right)$.

Lemma 2.3. (see [30]) Using Lemmas 2.1 and 2.2, one can define a mapping $W$ of $C$ into itself as: $W x=\lim _{n \rightarrow \infty} W_{n} x=\lim _{n \rightarrow \infty} U_{n, 1} x$, for every $x \in C$. If $\left\{x_{n}\right\}$ is a bounded sequence in $C$, then we have

$$
\lim _{n \rightarrow \infty}\left\|W x_{n}-W_{n} x_{n}\right\|=0 .
$$

We also need the following well-known lemmas for proving our main results.

Lemma 2.4. ([31]) Let $C$ be a nonempty closed convex subset of a real Hilbert space $H$. Let $S: C \rightarrow C$ be a nonexpansive mapping with Fix $(S) \neq \varnothing$. Then $S$ is demiclosed on $C$, i.e., if $y_{n} \rightarrow z \in C$ weakly and $y_{n}-S y_{n} \rightarrow y$ strongly, then $(I-S) z=y$.

Lemma 2.5. ([32]) Let $C$ be a closed convex subset of $H$. Let $\left\{x_{n}\right\}$ be a sequence in $H$ and $u \in H$. Let $q=P_{C}[u]$. If $\left\{x_{n}\right\}$ is such that $\omega_{w}\left(x_{n}\right) \subset C$ and satisfies the condition

$$
\left\|x_{n}-u\right\| \leq\|u-q\| \text { for all } n \text {. }
$$

Then $x_{n} \rightarrow q$.

We adopt the following notation:

- For a given sequence $\left\{x_{n}\right\} \subset H, \omega_{w}\left(x_{n}\right)$ denotes the weak $\omega$-limit set of $\left\{x_{n}\right\}$; that is, $\omega_{w}\left(x_{n}\right):=\left\{x \in H:\left\{x_{n_{j}}\right\}\right.$ converges weakly to $x$ for some subsequence $\left\{n_{j}\right\}$ of $\left.\{n\}\right\}$.

- $x_{n} \rightarrow x$ stands for the weak convergence of $\left(x_{n}\right)$ to $x$;

- $x_{n} \rightarrow x$ stands for the strong convergence of $\left(x_{n}\right)$ to $x$.

\section{Main results}

In this section we will state and prove our main results.

Theorem 3.1. Let $C$ be a nonempty closed convex subset of a real Hilbert space $H$. Let $A: C \rightarrow H$ be a monotone, k-Lipschitz-continuous mapping and let $\left\{S_{n}\right\}_{n=1}^{\infty}$ be an infinite family of nonexpansive mappings of $C$ into itself such that $\bigcap_{n=1}^{\infty} \operatorname{Fix}\left(S_{n}\right) \cap \Omega \neq \emptyset$. Let $x_{1}=x_{0} \in C$. For $C_{1}=C$, let $\left\{x_{n}\right\},\left\{y_{n}\right\}$ and $\left\{z_{n}\right\}$ be sequences generated by

$$
\begin{aligned}
& y_{n}=P_{C_{n}}\left[x_{n}-\lambda_{n} A x_{n}\right], \\
& z_{n}=\alpha_{n} x_{n}+\left(1-\alpha_{n}\right) W_{n} P_{C_{n}}\left[x_{n}-\lambda_{n} A y_{n}\right], \\
& C_{n+1}=\left\{z \in C_{n}:\left\|z_{n}-z\right\| \leq\left\|x_{n}-z\right\|\right\}, \\
& x_{n+1}=P_{C_{n+1}}\left[x_{0}\right], n \geq 1,
\end{aligned}
$$

where $W_{n}$ is $W$-mapping defined by (2.1). Assume the following conditions hold: 
(i) $\left\{\lambda_{n}\right\} \subset[a, b]$ for some $a, b \in(0,1 / k)$;

(ii) $\left\{\alpha_{n}\right\} \subset[0, c]$ for some $c \in[0,1)$.

Then the sequences $\left\{x_{n}\right\},\left\{y_{n}\right\}$ and $\left\{z_{n}\right\}$ generated by (3.1) converge strongly to the same point $P_{\bigcap_{n=1}^{\infty} \operatorname{Fix}\left(S_{n}\right) \cap \Omega}\left[x_{0}\right]$.

Next, we will divide our detail proofs into several conclusions. In the sequel, we assume that all assumptions of Theorem 3.1 are satisfied.

Conclusion 3.2. (1) Every $C_{n}$ is closed and convex, $n \geq 1$;

(2) $\bigcap_{n=1}^{\infty} \operatorname{Fix}\left(S_{n}\right) \cap \Omega \subset C_{n+1}, \forall_{n} \geq 1$,

(3) $\left\{x_{n+1}\right\}$ is well defined.

Proof. First we note that $C_{1}=C$ is closed and convex. Assume that $C_{k}$ is closed and convex. From (3.1), we can rewrite $C_{k+1}$ as

$$
C_{k+1}=\left\{z \in C_{k}:\left\langle z-\frac{x_{k}+z_{k}}{2}, z_{k}-x_{k}\right\rangle \geq 0\right\} .
$$

It is clear that $C_{k+1}$ is a half space. Hence, $C_{k+1}$ is closed and convex. By induction, we deduce that $C_{n}$ is closed and convex for all $n \geq 1$. Next we show that $\bigcap_{n=1}^{\infty} \operatorname{Fix}\left(S_{n}\right) \cap \Omega \subset C_{n+1}, \forall_{n} \geq 1$.

Set $t_{n}=P_{C_{n}}\left[x_{n}-\lambda_{n} A y_{n}\right]$ for all $n \geq 1$. Pick up $u \in \bigcap_{n=1}^{\infty} \operatorname{Fix}\left(S_{n}\right) \cap \Omega$. From property (iii) of $P_{C}$, we have

$$
\begin{aligned}
\left\|t_{n}-u\right\|^{2} & \leq\left\|x_{n}-\lambda_{n} A y_{n}-u\right\|^{2}-\left\|x_{n}-\lambda_{n} A y_{n}-t_{n}\right\|^{2} \\
& =\left\|x_{n}-u\right\|^{2}-\left\|x_{n}-t_{n}\right\|^{2}+2 \lambda_{n}\left\langle A y_{n}, u-t_{n}\right\rangle \\
& =\left\|x_{n}-u\right\|^{2}-\left\|x_{n}-t_{n}\right\|^{2}+2 \lambda_{n}\left\langle A y_{n}, u-y_{n}\right\rangle+2 \lambda_{n}\left\langle A y_{n}, y_{n}-t_{n}\right\rangle .
\end{aligned}
$$

Since $u \in \Omega$ and $y_{n} \in C_{n} \subset C$, we get

$$
\left\langle A u, y_{n}-u\right\rangle \geq 0 .
$$

This together with the monotonicity of $A$ imply that

$$
\left\langle A y_{n}, y_{n}-u\right\rangle \geq 0 \text {. }
$$

Combine (3.2) with (3.3) to deduce

$$
\begin{aligned}
\left\|t_{n}-u\right\|^{2} \leq & \left\|x_{n}-u\right\|^{2}-\left\|x_{n}-t_{n}\right\|^{2}+2 \lambda_{n}\left\langle A y_{n}, y_{n}-t_{n}\right\rangle \\
= & \left\|x_{n}-u\right\|^{2}-\left\|x_{n}-y_{n}\right\|^{2}-2\left\langle x_{n}-y_{n}, y_{n}-t_{n}\right\rangle-\left\|y_{n}-t_{n}\right\|^{2} \\
& +2 \lambda_{n}\left\langle A y_{n}, y_{n}-t_{n}\right\rangle \\
= & \left\|x_{n}-u\right\|^{2}-\left\|x_{n}-y_{n}\right\|^{2}-\left\|y_{n}-t_{n}\right\|^{2} \\
& +2\left\langle x_{n}-\lambda_{n} A y_{n}-y_{n}, t_{n}-y_{n}\right\rangle .
\end{aligned}
$$

Note that $y_{n}=P_{C_{n}}\left[x_{n}-\lambda_{n} A x_{n}\right]$ and $t_{n} \in C_{n}$. Then, using the property (ii) of $P_{C}$, we have

$$
\left\langle x_{n}-\lambda_{n} A x_{n}-y_{n}, t_{n}-y_{n}\right\rangle \leq 0 .
$$

Hence,

$$
\begin{aligned}
\left\langle x_{n}-\lambda_{n} A y_{n}-y_{n}, t_{n}-y_{n}\right\rangle & =\left\langle x_{n}-\lambda_{n} A x_{n}-y_{n}, t_{n}-y_{n}\right\rangle+\left\langle\lambda_{n} A x_{n}-\lambda_{n} A y_{n}, t_{n}-y_{n}\right\rangle \\
& \leq\left\langle\lambda_{n} A x_{n}-\lambda_{n} A y_{n}, t_{n}-y_{n}\right\rangle \\
& \leq \lambda_{n} k\left\|x_{n}-y_{n}\right\|\left\|t_{n}-y_{n}\right\| .
\end{aligned}
$$


From (3.4) and (3.5), we get

$$
\begin{aligned}
\left\|t_{n}-u\right\|^{2} & \leq\left\|x_{n}-u\right\|^{2}-\left\|x_{n}-y_{n}\right\|^{2}-\left\|y_{n}-t_{n}\right\|^{2}+2 \lambda_{n} k\left\|x_{n}-y_{n}\right\|\left\|t_{n}-y_{n}\right\| \\
& \leq\left\|x_{n}-u\right\|^{2}-\left\|x_{n}-y_{n}\right\|^{2}-\left\|y_{n}-t_{n}\right\|^{2}+\lambda_{n}^{2} k^{2}\left\|x_{n}-y_{n}\right\|^{2}+\left\|y_{n}-t_{n}\right\|^{2} \\
& =\left\|x_{n}-u\right\|^{2}+\left(\lambda_{n}^{2} k^{2}-1\right)\left\|x_{n}-y_{n}\right\|^{2} \\
& \leq\left\|x_{n}-u\right\|^{2} .
\end{aligned}
$$

Therefore, from (3.6), together with $z_{n}=\alpha_{n} x_{n}+\left(\begin{array}{ll}1 & \alpha_{n}\end{array}\right) W_{n} t_{n}$ and $u=W_{n} u$, we get

$$
\begin{aligned}
\left\|z_{n}-u\right\|^{2} & =\left\|\alpha_{n}\left(x_{n}-u\right)+\left(1-\alpha_{n}\right)\left(W_{n} t_{n}-u\right)\right\|^{2} \\
& \leq \alpha_{n}\left\|x_{n}-u\right\|^{2}+\left(1-\alpha_{n}\right)\left\|W_{n} t_{n}-u\right\|^{2} \\
& \leq \alpha_{n}\left\|x_{n}-u\right\|^{2}+\left(1-\alpha_{n}\right)\left\|t_{n}-u\right\|^{2} \\
& \leq\left\|x_{n}-u\right\|^{2}+\left(1-\alpha_{n}\right)\left(\lambda_{n}^{2} k^{2}-1\right)\left\|x_{n}-y_{n}\right\|^{2} \\
& \leq\left\|x_{n}-u\right\|^{2}
\end{aligned}
$$

which implies that

$$
u \in C_{n+1} .
$$

Therefore,

$$
\bigcap_{n=1}^{\infty} \operatorname{Fix}\left(S_{n}\right) \cap \Omega \subset C_{n+1}, \forall n \geq 1 .
$$

This implies that $\left\{x_{n+1}\right\}$ is well defined. $\square$

Conclusion 3.3. The sequences $\left\{x_{n}\right\},\left\{z_{n}\right\}$ and $\left\{t_{n}\right\}$ are all bounded and $\lim _{n \rightarrow \infty}\left\|x_{n}-x_{0}\right\|$ exists.

Proof. From $x_{n+1}=P_{C_{n+1}}\left[x_{0}\right]$, we have

$$
\left\langle x_{0}-x_{n+1}, x_{n+1}-y\right\rangle \geq 0, \forall y \in C_{n+1} .
$$

Since $\bigcap_{n=1}^{\infty} \operatorname{Fix}\left(S_{n}\right) \cap \Omega \subset C_{n+1}$, we also have

$$
\left\langle x_{0}-x_{n+1}, x_{n+1}-u\right\rangle \geq 0, \forall u \in \bigcap_{n=1}^{\infty} \operatorname{Fix}\left(S_{n}\right) \cap \Omega .
$$

So, for $u \in \bigcap_{n=1}^{\infty} \operatorname{Fix}\left(S_{n}\right) \cap \Omega$, we have

$$
\begin{aligned}
0 & \leq\left\langle x_{0}-x_{n+1}, x_{n+1}-u\right\rangle \\
& =\left\langle x_{0}-x_{n+1}, x_{n+1}-x_{0}+x_{0}-u\right\rangle \\
& =-\left\|x_{0}-x_{n+1}\right\|^{2}+\left\langle x_{0}-x_{n+1}, x_{0}-u\right\rangle \\
& \leq-\left\|x_{0}-x_{n+1}\right\|^{2}+\left\|x_{0}-x_{n+1}\right\|\left\|x_{0}-u\right\| .
\end{aligned}
$$

Hence,

$$
\left\|x_{0}-x_{n+1}\right\| \leq\left\|x_{0}-u\right\|, \forall u \in \bigcap_{n=1}^{\infty} \operatorname{Fix}\left(S_{n}\right) \cap \Omega,
$$

which implies that $\left\{x_{n}\right\}$ is bounded. From (3.6) and (3.7), we can deduce that $\left\{z_{n}\right\}$ and $\left\{t_{n}\right\}$ are also bounded.

From $x_{n}=P_{C_{n}}\left[x_{0}\right]$ and $x_{n+1}=P_{C_{n+1}}\left[x_{0}\right] \in C_{n+1} \subset C_{n}$, we have

$$
\left\langle x_{0}-x_{n}, x_{n}-x_{n+1}\right\rangle \geq 0 .
$$


As above one can obtain that

$$
0 \leq-\left\|x_{0}-x_{n}\right\|^{2}+\left\|x_{0}-x_{n}\right\|\left\|x_{0}-x_{n+1}\right\|,
$$

and therefore

$$
\left\|x_{0}-x_{n}\right\| \leq\left\|x_{0}-x_{n+1}\right\| .
$$

This together with the boundedness of the sequence $\left\{x_{n}\right\}$ imply that $\lim _{n \rightarrow \infty}\left\|x_{n}-x_{0}\right\|$ exists.

Conclusion 3.4. $\lim _{n \rightarrow \infty}|| x_{n+1}-x_{n}||=\lim _{n \rightarrow \infty}|| x_{n}-y_{n}||=\lim _{n \rightarrow \infty}|| x_{n}-z_{n}||=$ $\lim _{n \rightarrow \infty}|| x_{n}-t_{n} \|=0$ and $\lim _{n \rightarrow \infty}|| x_{n}-W_{n} x_{n}\left\|=\lim _{n \rightarrow \infty}|| x_{n}-W x_{n}\right\|=0$.

Proof. It is well known that in Hilbert spaces $H$, the following identity holds:

$$
\|x-y\|^{2}=\|x\|^{2}-\|y\|^{2}-2\langle x-y, y\rangle, \quad \forall x, y \in H .
$$

Therefore,

$$
\begin{aligned}
\left\|x_{n+1}-x_{n}\right\|^{2} & =\left\|\left(x_{n+1}-x_{0}\right)-\left(x_{n}-x_{0}\right)\right\|^{2} \\
& =\left\|x_{n+1}-x_{0}\right\|^{2}-\left\|x_{n}-x_{0}\right\|^{2}-2\left\langle x_{n+1}-x_{n}, x_{n}-x_{0}\right\rangle,
\end{aligned}
$$

and by (3.9)

$$
\left\|x_{n+1}-x_{n}\right\|^{2} \leq\left\|x_{n+1}-x_{0}\right\|^{2}-\left\|x_{n}-x_{0}\right\|^{2} .
$$

Since $\lim _{n \rightarrow \infty}\left\|x_{n}-x_{0}\right\|$ exists, we get $\left\|x_{n+1}-x_{0}\right\|^{2}-\left\|x_{n}-x_{0}\right\|^{2} \rightarrow 0$. Therefore,

$$
\lim _{n \rightarrow \infty}\left\|x_{n+1}-x_{n}\right\|=0 \text {. }
$$

Since $x_{n+1} \in C_{n}$, we have

$$
\left\|z_{n}-x_{n+1}\right\| \leq\left\|x_{n}-x_{n+1}\right\|,
$$

and hence

$$
\begin{aligned}
\left\|x_{n}-z_{n}\right\| & \leq\left\|x_{n}-x_{n+1}\right\|+\left\|x_{n+1}-z_{n}\right\| \\
& \leq 2\left\|x_{n+1}-x_{n}\right\| \\
& \rightarrow 0 .
\end{aligned}
$$

For each $u \in \bigcap_{n=1}^{\infty} \operatorname{Fix}\left(S_{n}\right) \cap \Omega$, from (3.7), we have

$$
\begin{aligned}
\left\|x_{n}-y_{n}\right\|^{2} & \leq \frac{1}{\left(1-\alpha_{n}\right)\left(1-\lambda_{n}^{2} k^{2}\right)}\left(\left\|x_{n}-u\right\|^{2}-\left\|z_{n}-u\right\|^{2}\right) \\
& \leq \frac{1}{\left(1-\alpha_{n}\right)\left(1-\lambda_{n}^{2} k^{2}\right)}\left(\left\|x_{n}-u\right\|+\left\|z_{n}-u\right\|\right)\left\|x_{n}-z_{n}\right\| .
\end{aligned}
$$

Since $\left\|x_{n}-z_{n}\right\| \rightarrow 0$ and the sequences $\left\{x_{n}\right\}$ and $\left\{z_{n}\right\}$ are bounded, we obtain $\| x_{n}$ $y_{n} \| \rightarrow 0$.

We note that following the same idea as in (3.6) one obtains that

$$
\left\|t_{n}-u\right\|^{2} \leq\left\|x_{n}-u\right\|^{2}+\left(\lambda_{n}^{2} k^{2}-1\right)\left\|y_{n}-t_{n}\right\|^{2} .
$$

Hence,

$$
\begin{aligned}
\left\|z_{n}-u\right\|^{2} & \leq \alpha_{n}\left\|x_{n}-u\right\|^{2}+\left(1-\alpha_{n}\right)\left\|t_{n}-u\right\|^{2} \\
& \leq \alpha_{n}\left\|x_{n}-u\right\|^{2}+\left(1-\alpha_{n}\right)\left(\left\|x_{n}-u\right\|^{2}+\left(\lambda_{n}^{2} k^{2}-1\right)\left\|y_{n}-t_{n}\right\|^{2}\right) \\
& =\left\|x_{n}-u\right\|^{2}+\left(1-\alpha_{n}\right)\left(\lambda_{n}^{2} k^{2}-1\right)\left\|y_{n}-t_{n}\right\|^{2} .
\end{aligned}
$$


It follows that

$$
\begin{aligned}
\left\|t_{n}-y_{n}\right\|^{2} & \leq \frac{1}{\left(1-\alpha_{n}\right)\left(1-\lambda_{n}^{2} k^{2}\right)}\left(\left\|x_{n}-u\right\|^{2}-\left\|z_{n}-u\right\|^{2}\right) \\
& \leq \frac{1}{\left(1-\alpha_{n}\right)\left(1-\lambda_{n}^{2} k^{2}\right)}\left(\left\|x_{n}-u\right\|+\left\|z_{n}-u\right\|\right)\left\|x_{n}-z_{n}\right\| \\
& \rightarrow 0 .
\end{aligned}
$$

Since $A$ is $k$-Lipschitz-continuous, we have $\left\|A y_{n}-A t_{n}\right\| \rightarrow 0$. From

$$
\left\|x_{n}-t_{n}\right\| \leq\left\|x_{n}-y_{n}\right\|+\left\|y_{n}-t_{n}\right\|,
$$

we also have

$$
\left\|x_{n}-t_{n}\right\| \rightarrow 0
$$

Since $z_{n}=\alpha_{n} x_{n}+\left(1-\alpha_{n}\right) W_{n} t_{n}$, we have

$$
\left(1-\alpha_{n}\right)\left(W_{n} t_{n}-t_{n}\right)=\alpha_{n}\left(t_{n}-x_{n}\right)+\left(z_{n}-t_{n}\right) .
$$

Then,

$$
\begin{aligned}
(1-c)\left\|W_{n} t_{n}-t_{n}\right\| & \leq\left(1-\alpha_{n}\right)\left\|W_{n} t_{n}-t_{n}\right\| \\
& \leq \alpha_{n}\left\|t_{n}-x_{n}\right\|+\left\|z_{n}-t_{n}\right\| \\
& \leq\left(1+\alpha_{n}\right)\left\|t_{n}-x_{n}\right\|+\left\|z_{n}-x_{n}\right\|
\end{aligned}
$$

and hence $\left\|t_{n}-W_{n} t_{n}\right\| \rightarrow 0$. To conclude,

$$
\begin{aligned}
\left\|x_{n}-W_{n} x_{n}\right\| & \leq\left\|x_{n}-t_{n}\right\|+\left\|t_{n}-W_{n} t_{n}\right\|+\left\|W_{n} t_{n}-W_{n} x_{n}\right\| \\
& \leq\left\|x_{n}-t_{n}\right\|+\left\|t_{n}-W_{n} t_{n}\right\|+\left\|t_{n}-x_{n}\right\| \\
& \leq 2\left\|x_{n}-t_{n}\right\|+\left\|t_{n}-W_{n} t_{n}\right\| .
\end{aligned}
$$

So, $\left\|x_{n}-W_{n} x_{n}\right\| \rightarrow 0$ too. On the other hand, since $\left\{x_{n}\right\}$ is bounded, from Lemma 2.3, we have $\lim _{n \rightarrow \infty}\left\|W_{n} x_{n}-W x_{n}\right\|=0$. Therefore, we have

$$
\lim _{n \rightarrow \infty}\left\|x_{n}-W x_{n}\right\|=0
$$

$\square$

Finally, according to Conclusions 3.3-3.5, we prove the remainder of Theorem 3.1.

Proof. By Conclusions 3.3-3.5, we have proved that

$$
\lim _{n \rightarrow \infty}\left\|x_{n}-W x_{n}\right\|=0 .
$$

Furthermore, since $\left\{x_{n}\right\}$ is bounded, it has a subsequence $\left\{x_{n_{j}}\right\}$ which converges weakly to some $\tilde{u} \in C$; hence, we have $\lim _{j \rightarrow \infty}\left\|x_{n_{j}}-W x_{n_{j}}\right\|=0$. Note that, from Lemma 2.4, it follows that $I-W$ is demiclosed at zero. Thus $\tilde{u} \in \operatorname{Fix}(W)$. Since $t_{n}=P_{C_{n}}\left[x_{n}-\lambda_{n} A y_{n}\right]$, for every $x \in C_{n}$ we have

$$
\left\langle x_{n}-\lambda_{n} A y_{n}-t_{n}, t_{n}-x\right\rangle \geq 0
$$

hence,

$$
\left\langle x-t_{n}, A y_{n}\right\rangle \geq\left\langle x-t_{n}, \frac{x_{n}-t_{n}}{\lambda_{n}}\right\rangle .
$$


Combining with monotonicity of $A$ we obtain

$$
\begin{aligned}
\left\langle x-t_{n}, A x\right\rangle & \geq\left\langle x-t_{n}, A t_{n}\right\rangle \\
& =\left\langle x-t_{n}, A t_{n}-A y_{n}\right\rangle+\left\langle x-t_{n}, A y_{n}\right\rangle \\
& \geq\left\langle x-t_{n}, A t_{n}-A y_{n}\right\rangle+\left\langle x-t_{n}, \frac{x_{n}-t_{n}}{\lambda_{n}}\right\rangle .
\end{aligned}
$$

Since $\lim _{n \rightarrow \infty}\left(x_{n}-t_{n}\right)=\lim _{n \rightarrow \infty}\left(y_{n}-t_{n}\right)=0, A$ is Lipschitz continuous and $\lambda_{n} \geq a>0$, we deduce that

$$
\langle x-\tilde{u}, A x\rangle=\lim _{n_{j} \rightarrow \infty}\left\langle x-t_{n_{j}}, A x\right\rangle \geq 0 .
$$

This implies that $\tilde{u} \in \Omega$. Consequently, $\tilde{u} \in \bigcap_{n=1}^{\infty} \operatorname{Fix}\left(S_{n}\right) \cap \Omega$ That is, $\omega_{w}\left(x_{n}\right) \subset \bigcap_{n=1}^{\infty} \operatorname{Fix}\left(S_{n}\right) \cap \Omega$.

In (3.8), if we take $u=P_{\bigcap_{n=1}^{\infty} \operatorname{Fix}\left(S_{n}\right) \cap \Omega}\left[x_{0}\right]$, we get

$$
\left\|x_{0}-x_{n+1}\right\| \leq\left\|x_{0}-P_{\bigcap_{n=1}^{\infty} \operatorname{Fix}\left(S_{n}\right) \cap \Omega}\left[x_{0}\right]\right\| .
$$

Notice that $\omega_{w}\left(x_{n}\right) \subset \bigcap_{n=1}^{\infty} \operatorname{Fix}\left(S_{n}\right) \cap \Omega$. Then, (3.10) and Lemma 2.5 ensure the strong convergence of $\left\{x_{n+1}\right\}$ to $P_{\bigcap_{n=1}^{\infty} F i x\left(S_{n}\right) \cap \Omega}\left[x_{0}\right]$. Consequently, $\left\{y_{n}\right\}$ and $\left\{z_{n}\right\}$ also converge strongly to $P_{\bigcap_{n=1}^{\infty} F i x\left(S_{n}\right) \cap \Omega}\left[x_{0}\right]$. This completes the proof.

Remark 3.5. Our algorithm (3.1) is simpler than the one in [23] and we extend the single mapping in [23] to an infinite family mappings. At the same time, the proofs are also simple.

\section{Acknowledgements}

The authors are extremely grateful to the referees for their useful comments and suggestions which helped to improve this paper. Yonghong Yao was supported in part by Colleges and Universities Science and Technology Development Foundation (20091003) of Tianjin, NSFC 11071279 and NSFC 71161001-G0105. Yeong-Cheng Liou was supported in part by NSC 100-2221-E-230-012. Jen-Chih Yao was partially supported by the Grant NSC 99-2115-M-037002-MY3.

\section{Author details}

${ }^{1}$ Department of Mathematics, Tianjin Polytechnic University, Tianjin 300387, China ${ }^{2}$ Department of Information Management, Cheng Shiu University, Kaohsiung 833, Taiwan ${ }^{3}$ Department of Applied Mathematics, Chung Yuan Christian University, Chung Li 32023, Taiwan ${ }^{4}$ Center for General Education, Kaohsiung Medical University, Kaohsiung 807, Taiwan

\section{Authors' contributions}

All authors participated in the design of the study and performed the converegnce analysis. All authors read and approved the final manuscript.

\section{Competing interests}

The authors declare that they have no competing interests.

Received: 14 March 2011 Accepted: 17 September 2011 Published: 17 September 2011

\section{References}

1. Stampacchia, G: Formes bilineaires coercitives sur les ensembles convexes. CR Acad Sci Paris. 258, 4413-4416 (1964)

2. Lions, JL, Stampacchia, G: Variational inequalities. Comm Pure Appl Math. 20, $493-517$ (1967). doi:10.1002/ cpa.3160200302

3. Glowinski, R: Numerical methods for nonlinear variational problems. Springer, New York (1984)

4. Iusem, AN: An iterative algorithm for the variational inequality problem. Comput Appl Math. 13, 103-114 (1994)

5. Yao, JC: Variational inequalities with generalized monotone operators. Math Oper Res. 19, $691-705$ (1994). doi:10.1287/ moor.19.3.691

6. Korpelevich, GM: An extragradient method for finding saddle points and other problems. Ekonomika i Matematicheskie Metody. 12, 747-756 (1976)

7. Yao, Y, Noor, MA: On viscosity iterative methods for variational inequalities. J Math Anal Appl. 325, 776-787 (2007). doi:10.1016/j.jmaa.2006.01.091

8. Yao, Y, Noor, MA: On modified hybrid steepest-descent methods for general variational inequalities. J Math Anal Appl. 334, 1276-1289 (2007). doi:10.1016/j.jmaa.2007.01.036 
9. $\mathrm{Xu}, \mathrm{HK}, \mathrm{Kim}, \mathrm{TH}$ : Convergence of hybrid steepest-descent methods for variational inequalities. J Optimiz Theory Appl. 119(1), 185-201 (2003)

10. Takahashi, W, Toyoda, M: Weak convergence theorems for nonexpansive mappings and monotone mappings. J Optim Theory Appl. 118, 417-428 (2003). doi:10.1023/A:1025407607560

11. Antipin, AS: Methods for solving variational inequalities with related constraints. Comput Math Math Phys. 40 1239-1254 (2007)

12. Yao, Y, Yao, JC: On modified iterative method for nonexpansive mappings and monotone mappings. Appl Math Comput. 186, 1551-1558 (2007). doi:10.1016/j.amc.2006.08.062

13. Yao, Y, Noor, MA: On modified hybrid steepest-descent method for variational inequalities. Carpathian J Math. 24 139-148 (2008)

14. He, BS, Yang, ZH, Yuan, XM: An approximate proximal-extragradient type method for monotone variational inequalities. J Math Anal Appl. 300, 362-374 (2004). doi:10.1016/j.jmaa.2004.04.068

15. Facchinei, F, Pang, JS: Finite-dimensional variational inequalities and complementarity problems. In Springer Series in Operations Research, vol. I and II,Springer, New York (2003)

16. Ceng, LC, Yao, JC: An extragradient-like approximation method for variational inequality problems and fixed point problems. Appl Math Comput. 1906, 206-215 (2007)

17. Ceng, LC, Yao, JC: Strong convergence theorem by an extragradient method for fixed point problems and variational inequality problems. Taiwan J Math. 10, 1293-1303 (2006)

18. Yao, Y, Liou, YC, Chen, R: Convergence theorems for fixed point problems and variational inequality problems in Hilbert spaces. Math Nachr. 282(12), 1827-1835 (2009). doi:10.1002/mana.200610817

19. Cianciaruso, F, Marino, G, Muglia, L, Yao, Y: On a two-step algorithm for hierarchical fixed Point problems and variational inequalities. J Inequal Appl 2009, 13 (2009). Article ID 208692

20. Cianciaruso, F, Colao, V, Muglia, L, Xu, HK: On an implicit hierarchical fixed point approach to variational inequalities. Bull Aust Math Soc.80, 117-124

21. Lu, X, Xu, HK, Yin, X: Hybrid methods for a class of monotone variational inequalities. Nonlinear Anal. 71, 1032-1041 (2009). doi:10.1016/j.na.2008.11.067

22. Yao, Y, Chen, $R, X u, H K$ : Schemes for finding minimum-norm solutions of variational inequalities. Nonlinear Anal. 72 3447-3456 (2010). doi:10.1016/j.na.2009.12.029

23. Nadezhkina, N, Takahashi, W: Strong convergence theorem by a hybrid method for nonexpansive mappings and Lipschitz-continuous monotone mappings. SIAM J Optim. 16, 1230-1241 (2006). doi:10.1137/050624315

24. Rockafellar, RT: Monotone operators and the proximal point algorithm. SIAM J Control Optim. 14, 877-898 (1976). doi:10.1137/0314056

25. Ceng, LC, Teboulle, M, Yao, JC: Weak convergence of an iterative method for pseu-domonotone variational inequalities and fixed point problems. J Optim Theory Appl. 146, 19-31 (2010). doi:10.1007/s10957-010-9650-0

26. Ceng, LC, Al-Homidan, S, Ansari, QH, Yao, J-C: An iterative scheme for equilibrium problems and fixed point problems of strict pseudo-contraction mappings. J Comput Appl Math. 223, 967-974 (2009). doi:10.1016/j.cam.2008.03.032

27. Martinez-Yanes, C, Xu, HK: Strong convergence of the CQ method for fixed point processes. Nonlinear Anal. 64, 2400-2411 (2006). doi:10.1016/j.na.2005.08.018

28. Ceng, LC, Hadjisavvas, N, Wong, NC: Strong convergence theorem by a hybrid extragradient-like approximation method for variational inequalities and fixed point problems. J Glob Optim. 46, 635-646 (2010). doi:10.1007/s10898-009-9454-7

29. Opial, Z: Weak convergence of the sequence of successive approximations of nonexpansive mappings. Bull Am Math Soc. 73, 595-597 (1967)

30. Shimoji, K, Takahashi, W: Strong convergence to common fixed points of infinite nonexpasnsive mappings and applications. Taiwan J Math. 5, 387-404 (2001)

31. Yao, Y, Liou, Y-C, Yao, J-C: Convergence theorem for equilibrium problems and fixed point problems of infinite family of nonexpansive mappings. Fixed Point Theory and Applications 2007, 12 (2007). Article ID 64363

32. Goebel, K, Kirk, WA: Topics in Metric Fixed Point Theory. In Cambridge Studies in Advanced Mathematics, vol. 28, Cambridge University Press, Cambridge (1990)

doi:10.1186/1687-1812-2011-53

Cite this article as: Yao et al: Strong convergence of a hybrid method for monotone variational inequalities and fixed point problems. Fixed Point Theory and Applications 2011 2011:53.

\section{Submit your manuscript to a SpringerOpen ${ }^{\circ}$ journal and benefit from:}

- Convenient online submission

- Rigorous peer review

- Immediate publication on acceptance

- Open access: articles freely available online

- High visibility within the field

- Retaining the copyright to your article

Submit your next manuscript at $\boldsymbol{\nabla}$ springeropen.com 